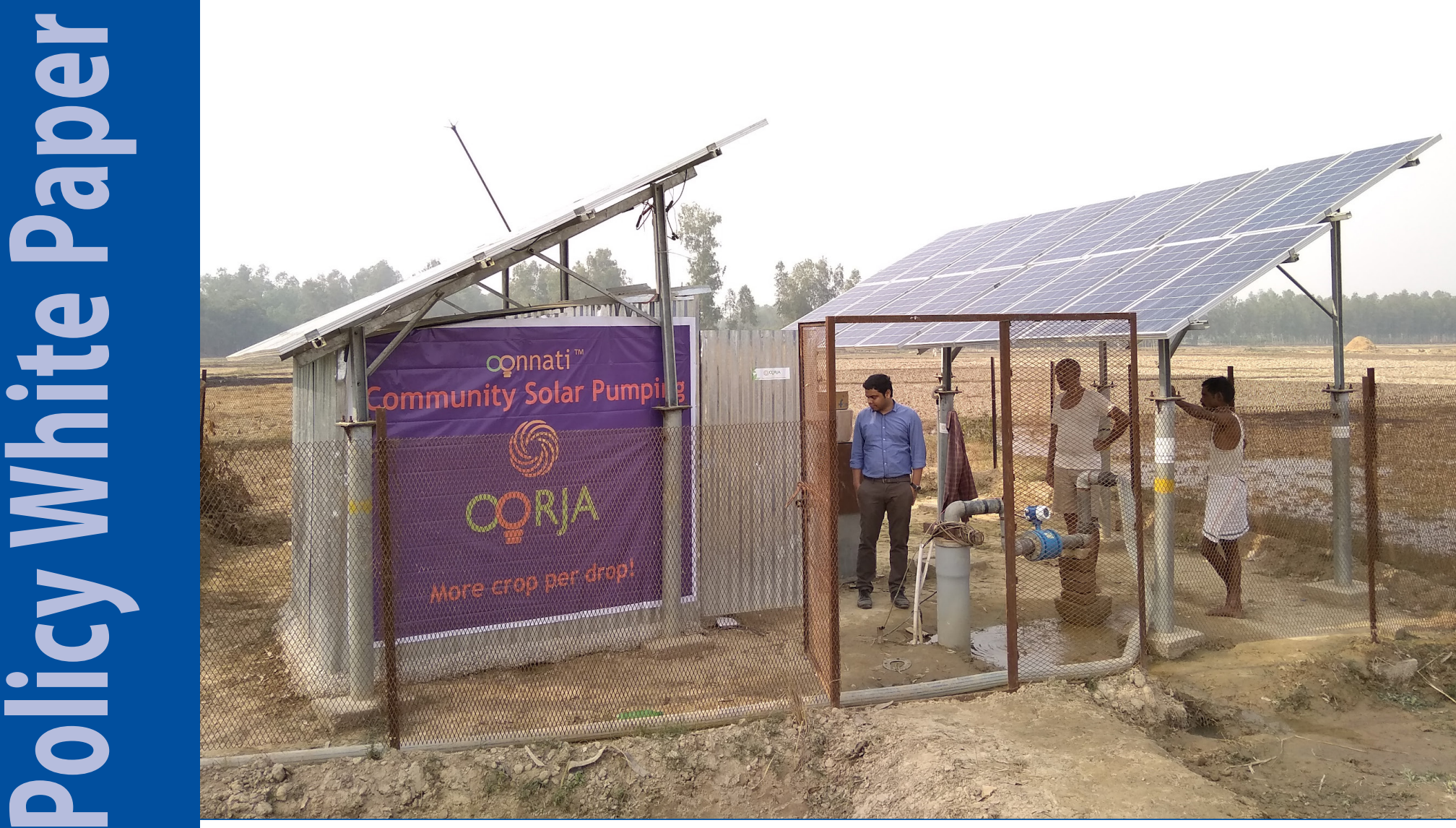

Oorja currently operates fifteen community solar pumps each of which deliver 250-320 cubic meters of irrigation water to smallholder farmers each day. Photo courtesy of Oorja.

\title{
Providing Clean Energy Solutions to India's Bottom of the Pyramid Population
}

\author{
By: Jill Howard, Fiona Wilson, and E. Hachemi Aliouche
}

December 22, 2020 


\section{Introduction}

Despite a scheme launched by the Indian government in 2017 that has declared achieving close to 100 percent electrification in the country, studies have shown that only 65 percent of rural enterprises in India report having electricity grid connection (Smart Power India, 2019). While millions of households have been positively impacted by access to electricity, small businesses and smallholder farmers (those with holdings of less than 2 acres) in rural India have been left out of the equation or receive very unreliable power supply. Byproducts of the energy poverty experienced by India's Bottom of the Pyramid (BoP) population include an enormous carbon footprint produced by the use of traditional fossil fuels such as diesel and kerosene, and economic stagnation as a result of the agrarian crisis in India.

Working to address each of these challenges is Oorja Development Solutions, a social enterprise established in 2016 with a mission to "substantially and cost-effectively scale last-mile distribution of integrated energy solutions to revitalize the agrarian economy, alleviate poverty, and fight climate change in rural India."

Through three pay-per-use integrated energy services along the agricultural value chain, Oorja is replacing the diesel economy and using clean energy as a catalyst for economic development and climate change mitigation. As Oorja has worked to refine and increase the impact of its model, the company has explored the possibility of social sector franchising. Social sector franchising applies proven concepts and systems of traditional franchising to mission-driven businesses in fields such as health care, clean energy, education, and nutritional access to broaden the reach of life-altering social services. A successful social sector franchisor leads a network of easily replicated, locally owned businesses under the same model, branding, and mission.

This case study explains Oorja Development Solutions' creation as well as the business model by which it operates. While Oorja does not currently have any franchisees, this case study explores why the company has considered implementing a franchising system as well as the reasons why it is not currently moving forward with the model. By also detailing the ingredients to Oorjas success and opportunities for future growth, this case study aims to provide insight into a successful social enterprise as well as the logic for choosing whether or not to execute a social sector franchising system.

\section{About This Case Study}

This case was examined as part of the Social Sector Franchise Initiative, a collaborative undertaking at the University of New Hampshire (UNH) between the Rosenberg International Franchise Center (a program of the Peter T. Paul College of Business \& Economics) and the Center for Social Innovation and Enterprise (now the Changemaker Collaborative), a joint venture between the Sustainability Institute, the Peter T. Paul College of Business and Economics, and the Carsey School of Public Policy. The International Franchise Association (IFA) is a key external partner.

A key part of the initiative, the Social Sector Franchise Accelerator (SSFA) was a nine-month program which ran from 2016 to 2019, where nascent social sector franchises were selected from a pool of applicants. Accelerator participants were provided with coordinated intensive mentorship by commercial franchise experts from the IFA, online learning, and an eco-system of support. The process included an active learning and research component conducted and documented by UNH faculty and students, culminating in a series of published case studies.

As of August 2020, Oorja has directly impacted over 1,500 lives in rural India by installing energy systems providing electricity, irrigation, and milling services. By delivering 58,013 cubic meters of irrigation water, the company has saved its consumers 60,524 Indian Rupees on diesel and has kept 15,845 kilograms of carbon dioxide equivalent (CO2eq) from being emitted into the atmosphere. It has also created seven local jobs.

\section{Context}

In 2017, the Indian government launched the "Saubhagya Scheme" to connect 25 million households to the national electric grid by January 2019 (REC India, 2019). While the program has seen success, close to 35 percent of rural enterprises in India are not connected and are instead relying on diesel engines for power. Most affected is the agricultural sector which 


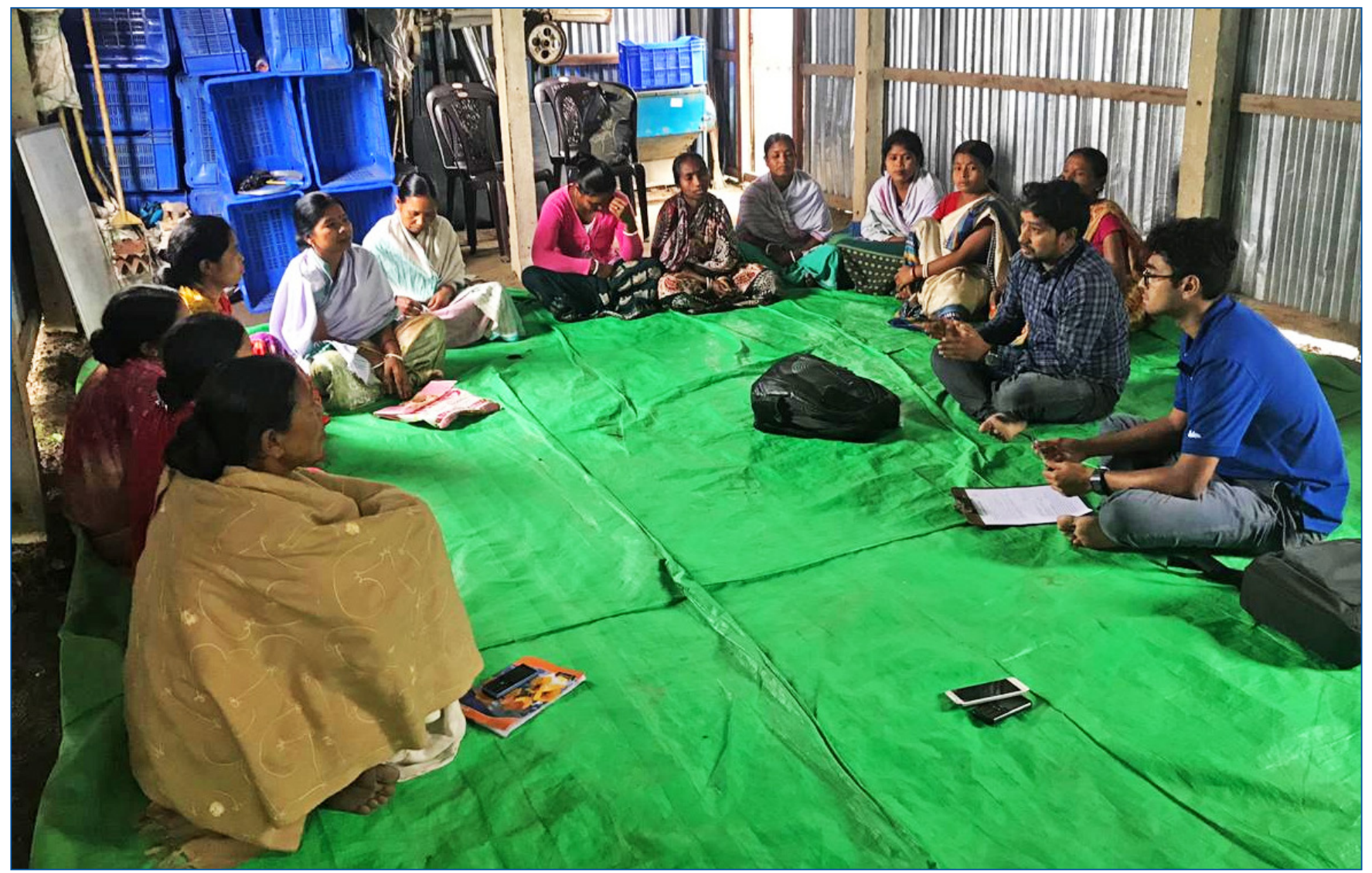

Oorja conducts extensive needs assessment focus group discussions and surveys before selecting the communities it serves. Photo courtesy of Oorja.

accounts for 18 percent of India's GDP yet provides income to almost half of the total workforce in the country. For the 450 million BoP Indians who receive fewer than six to eight hours of electricity supply per day, the grid is intermittent and unreliable. As a result, rural Indians spend 30 percent of their income on fossil fuels such as diesel for commercial power like irrigation pumps, and kerosene for household lighting (Sustainability Outlook, 2019).

While the high cost of fossil fuels leads to limited business hours and low productivity, many farmers face crop failure because only 49 percent of net sown area in India is irrigated, leaving the rest of the farms reliant on erratic rainwater. Nine million operationally expensive diesel pumps consume four billion liters of diesel per year, making water pumping for irrigation not only a difficult reality for adequate crop yields, but a major contributor to the climate crisis. In rural Indian communities most vulnerable to climate change, dependence on traditional fossil fuels has led to massive expenses on energy and a growing carbon footprint (Sandwell et al., 2016).

In areas with weak grid connection, smallholder farmers, small business owners, service providers, public institutions, and others reliant on affordable and reliable energy supplies are marginalized by India's current energy ecosystem. While these businesses have the potential to play a crucial role in economic development, lack of accessible services is a barrier. In the state of Uttar Pradesh alone, where Oorja operates, the potential number of replaceable diesel pumps is 1.8 million, with another 400,000 in the neighboring state of Bihar (Sandwell et al., 2016). An option for clean energy that truly caters to the BoP population in India presents a massive market crucial to stimulating economic development, addressing climate change, and offering pathways out of poverty. 


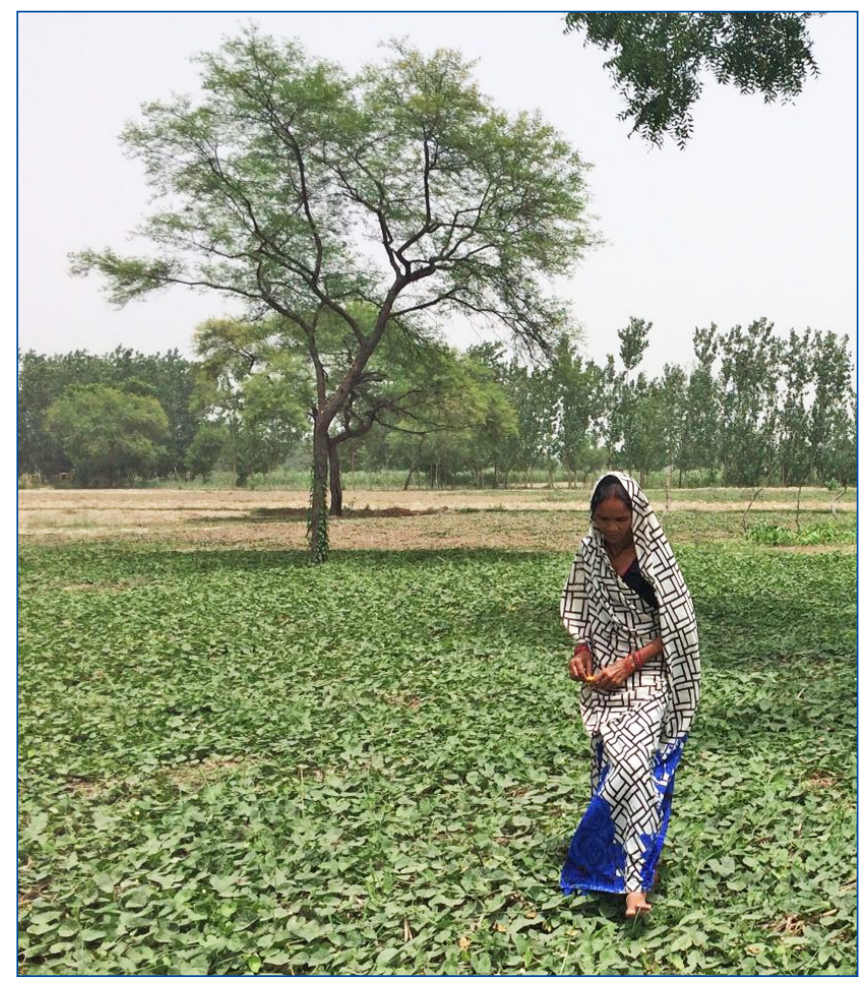

The agricultural sector accounts for $18 \%$ of India's GDP yet provides income to almost half of the total workforce in the country. Photo courtesy of Oorja.

\section{The Beginning of Oorja}

The genesis of Oorja Development Solutions occurred in 2015 at a European climate entrepreneurship workshop when Amit Saraogi, CEO, met his co-founder, Dr. Clementine Chambon, CTO. The pair originally began by creating their own technology through which they would use agricultural waste to generate electricity. After one and a half years of development, though, solar equipment prices dropped so dramatically that moving forward with the prototype was economically unviable. After deciding that solving the issues of energy poverty was more critical than bringing a new technology to the market, Amit and Clementine spent a year conducting extensive needs assessments in India's two largest and most energy poor states. After meeting with numerous stakeholders, potential partners, local officials, heads of villages, and community leaders, Amit and Clementine incorporated a UK holding company in August 2016 and established Oorja Development Solutions as a wholly-owned subsidiary in India in December 2016.
Having grown up alongside a large population living in extreme multidimensional poverty without access to basic services, Amit was compelled to combine his personal experiences and volunteer endeavors with his education in international development. Through Oorja Development Solutions, Amit has been able to do just that by empowering local communities to access basic services and live with dignity through a market-based approach. Oorja's first deployment of a smart solar minigrid was in a completely off-grid village. A mini-grid is an electricity distribution network that is independent of the public network. As of today, the mini-grid is still running successfully for 44 households with an average of six to eight family members each, ultimately providing uninterrupted clean energy to close to 350 people. While Oorja originally planned to only serve households, Amit and Clementine quickly learned that there was even greater demand from people who were looking to use the energy for productive uses like irrigation pumps, agroprocessing mills, and cold storages. Thus, Oorja pivoted its model to focus more on powering income-generating appliances that would more rapidly increase productivity and income for users and help rural economic development.

\section{Business Model}

In its aim to reach more energy-poor populations, Oorja has introduced three clean energy services. Each service is separately branded and operates on a pay-peruse basis without any upfront technology cost to the consumer. On-farm, Oorja provides Oonnati: a reliable community solar irrigation service that provides water year-round on demand to a group of 15 to 20 small farmers from each pump. Oorja also provides Oojjwal: an affordable solar milling service for farming communities to process grains. Finally, near-farm, Oorja is currently preparing to pilot Oonnayan: solar cold storage for vegetables and fruits grown by farmers who, without access to these types of facilities, lose 30 to 40 percent of their horticultural produce annually. Currently, Oorja is operating 15 community solar pumps, two agroprocessing mills, and one mini-grid in the states of Uttar Pradesh and Assam. In order to do so, the company has employed and trained six pump operators, one solar technician, and two sales and service agents. 


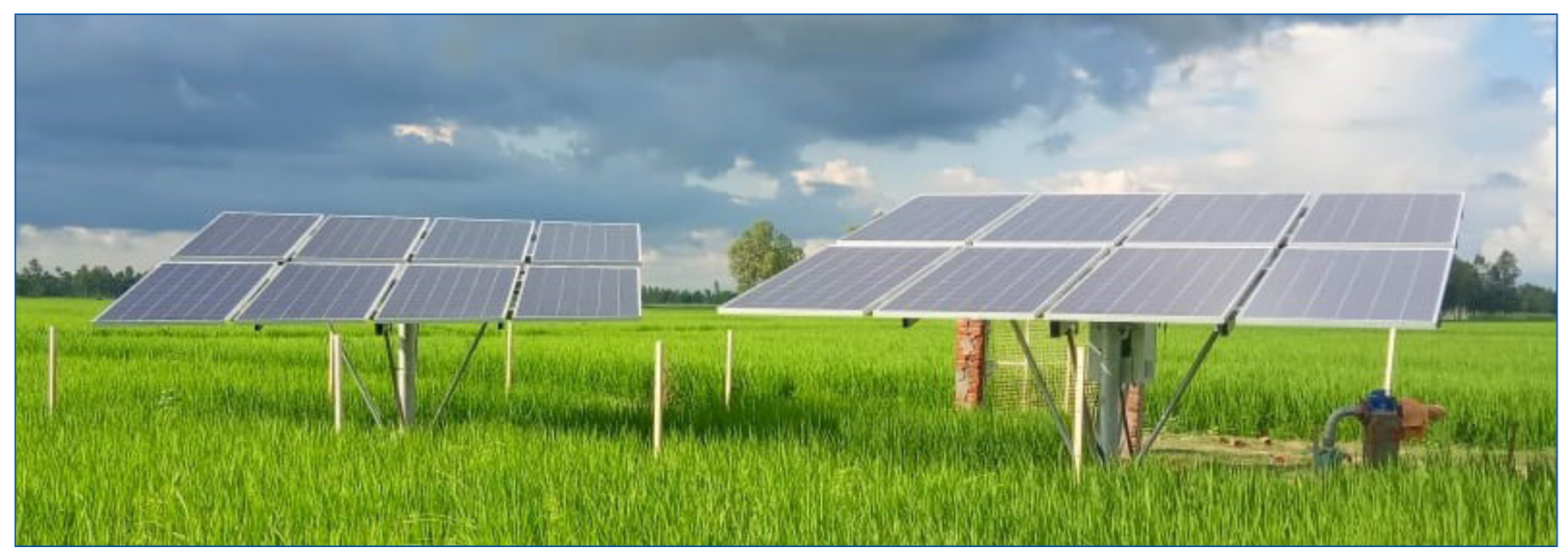

Oorja's 5 horsepower solar pumps provide reliable, affordable, and sustainable irrigation service to more than 250 farmers in order to maximize agricultural productivity and income. Photo courtesy of Oorja.

Operating on a business-to-consumer (B2C) model, Oorja conducts the site identification and selection, demand profiling, farmer group formation, customer sign-ups, system design and sizing, procurement, installation, testing and commissioning of the solar pumps, agroprocessing mills, and cold storages. Oorja enters rural BoP markets by identifying the most underserved districts that are off-grid or severely under-electrified using publicly available data and consultation with local government officials. Oorja conducts extensive needs assessments through focus groups and surveys, gathering information on ability and willingness to pay, crop selection and yield, water table depth, and current energy sources. Drawing on this information, Oorja selects communities to serve based on their need but also on their chances for financial sustainability. While the company is involved in the day-to-day operations and maintenance of its three services, Oorja also provides technical and operational training to local technicians and pump operators and partners with non-governmental organizations (NGOs) to facilitate community engagement and mobilization. This community-based solution allows any farmer near the deployed assets to access Oorja services without any upfront cost and at tariffs 20 percent cheaper than diesel power. Customer acquisition occurs through doorto-door campaigns, word-of-mouth, farmer producer organizations, local business committees, agricultural NGOs, and local media.

\section{An Innovative Theory of Change}

While there are competitors in each of the three segments that Oorja operates in, there are none that offer all three integrated clean energy solutions in the manner that Oorja does. While other companies sell the product directly to one farmer for their personal use, Oorja sells services that can be used by an entire community on a pay-per-use basis. Oorja chose to operate in this manner because they believe the model is more inclusive and it brings access to the low-income and marginal farmers who have been left out of more traditional efforts and subsidy schemes offered by the Indian government. These farmers cannot afford the upfront investment of even 20 percent that is required of them. With Oorja financing the capital cost of installing a solar pump, agroprocessing mill, or cold storage, BoP populations are finally able to access these life-changing technologies.

Competitors manufacture appliances and generally sell them as products to large farmers or NGOs, rather than offering a service. This effectively puts these products out of reach of the BoP population as they cannot afford to purchase these products. Otherwise, many companies only focus on one product and do not integrate their offerings as complementary services as Oorja does. By unifying its energy services along a value chain that employs almost half of India's working population, Oorja is able to maximize its market share and ability to create economic opportunity, improve the standard of living, and combat climate change in rural agrarian communities. 


\section{Franchising Approach}

In developing its services, Oorja has considered the social sector franchising method as a way to quickly scale its operations and impact. The standardization of Oorja's service offerings make it a prime candidate for the model. By franchising, Oorja franchisees would take over asset management, operations and maintenance, and customer service. In doing so, Oorja would be freed from the day-to-day operations of its services and effectively increase its financial sustain-

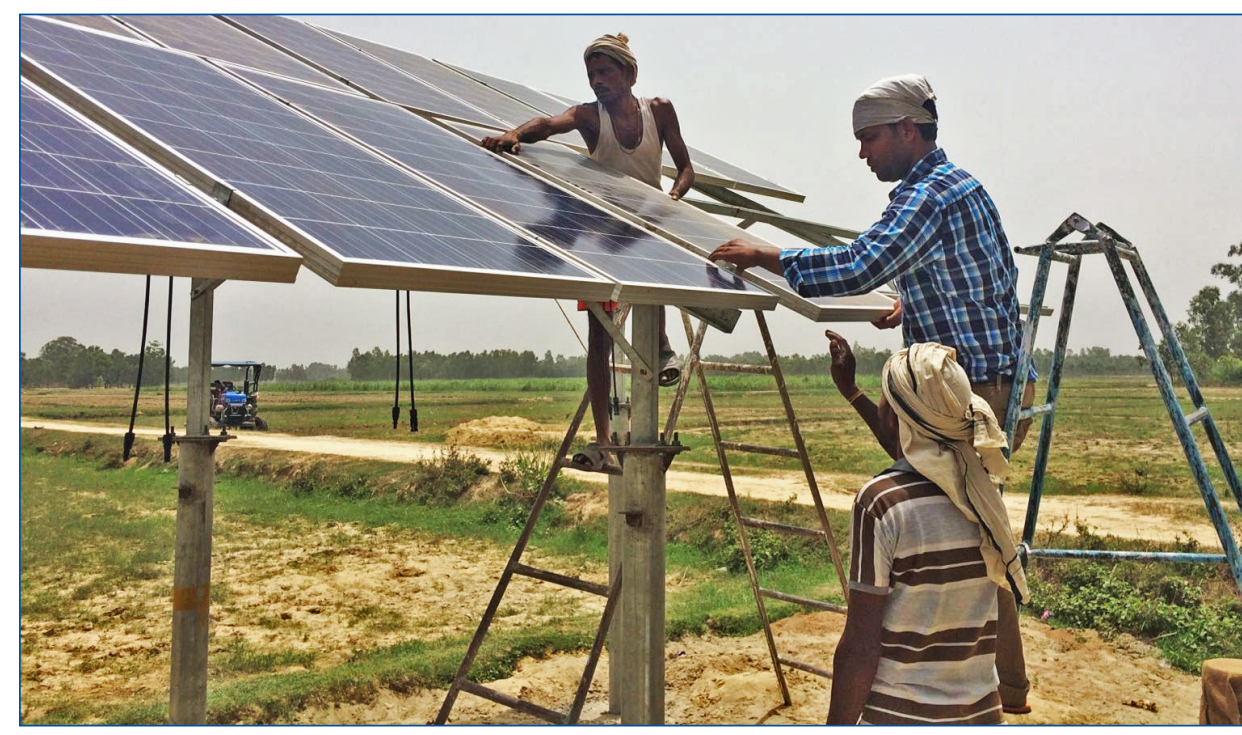

Oorja's first project in 2017, deployed to provide household electricity via a solar mini-grid, supplies clean energy to 44 households with an average of 6 to 8 family members each. While still running, Oorja's newer grids focus on serving the agricultural sector. Photo courtesy of Oorja. ability, efficiently deploy more solar pumps, agroprocessing mills and cold storages to reach economies of scale, and leverage the franchisees' position of trust and established networks within communities for rapid customer acquisition.

Because of the high up-front costs of implementing Oorja's energy systems mentioned previously, most potential franchisees are unable to afford the upfront costs. This major barrier to franchising has led Amit, Clementine, and the team at Oorja to delay implementing a franchising model. In the meantime, the company is working to foster partnerships with financial institutions to facilitate appliance financing for potential future franchisees. They are also refining and strengthening their core operations to ensure that once they do begin to scale up, the foundation of what is being franchised is robust.

Oorja already has some of the fundamental building blocks of a franchise system, including sufficient consumer demand, systemized processes, and the economics to support expansion. The areas that Oorja is now addressing are critical to any organization that is interested in building an effective franchising model. Since Oorja has different branding for each of its service offerings, it is essential that there be a strong brand recognition before rolling out franchising. Further, Oorja is looking to create more efficiencies in its supply chain and create a reasonable pricing system that would work with franchisees in place.

\section{Proving the Model: Oorja Development Solutions Impact}

Oorja has seen great success thus far and is well on its way to establishing a solid foundation for franchising. Currently, around 300 very small farmers are direct users of Oorja's service lines and from them, over 1,600 people are indirectly benefiting from these services. Through the delivery of irrigation water from solar pumps, processing of grains from the mills and electricity being provided from the mini-grid, 7,465 liters of kerosene and diesel have been saved and 19,432 kilograms of CO2eq have been kept from entering the atmosphere.

On a community and economic development level, Oorja has saved its users 20 percent expenditure on fossil fuels. One community member has been trained as a solar technician and six have been trained as pump operators. Overall, according to Oorja, there has been up to a 100 percent increase in user income and a 50 percent increase in agricultural yields. Oorja's impact data are impressive in evidencing the social, economic, and environmental benefits of its services. 


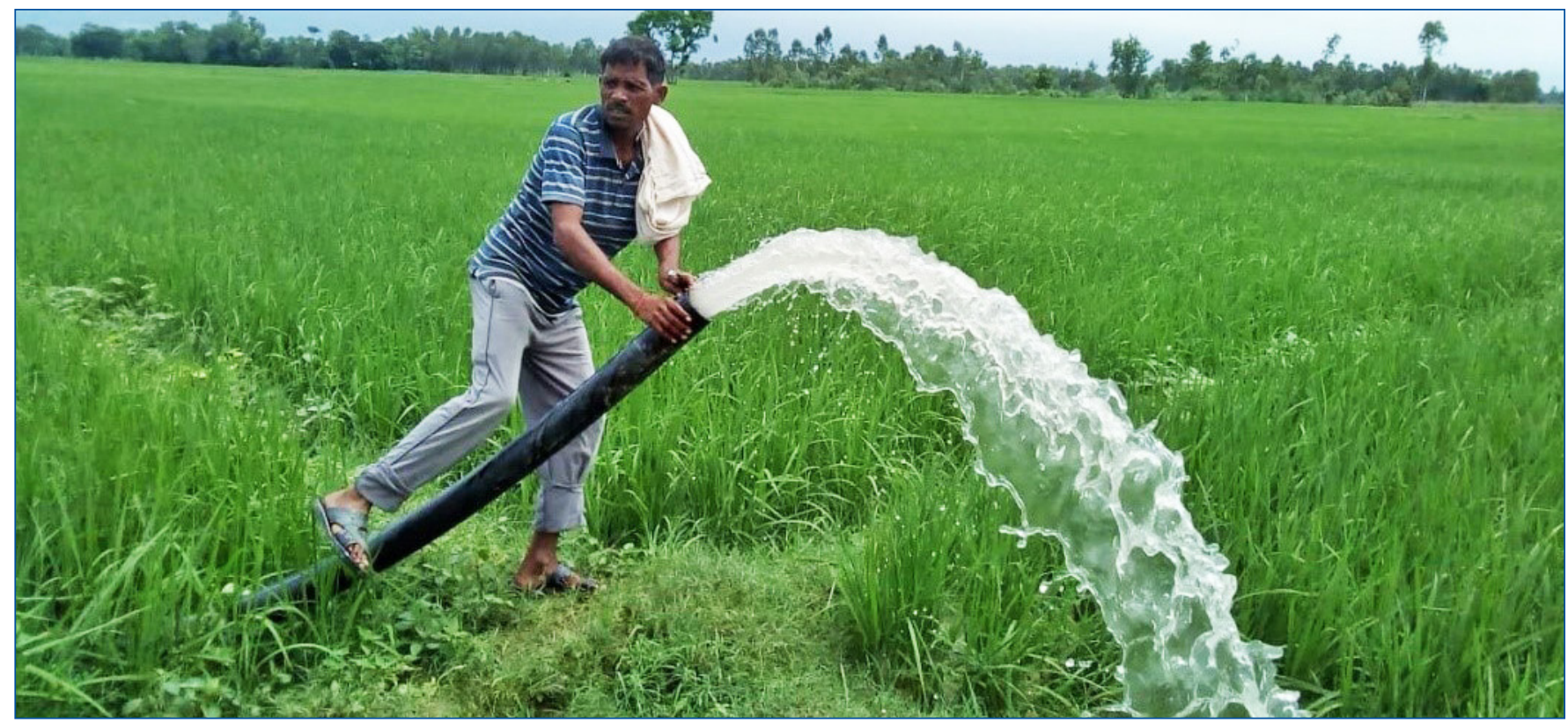

Pump operators who are locally hired and trained on water disbursement, payment collection, and providing customer service manage the solar pumps. Photo courtesy of Oorja.

\section{Looking Ahead for a Bold Future}

As Oorja continues to refine its model, the company has three major goals for the coming five years. First, it is committed to accelerating its impact and expanding geographically. Oorja is currently working in two Indian states and is moving toward a third and hopes to be established in six states within the next five years. Beyond geographical expansion, Oorja is exploring growing its service offering to other market segments that would still encompass reliable, affordable, and clean energy in last-mile rural markets. As the company expands, it will be important to have technology in place that allows Oorja to remotely monitor its equipment and operations from afar. Thus, Oorja is developing this proprietary technology to remotely monitor and control technical performance of its assets, integrate customer and impact data, facilitate digital payments, and provide more efficient customer service. Not only will this streamline operations, it will provide valuable information for strategic planning and investor reporting.

By decentralizing systems, decarbonizing the Indian economy, and moving toward digitalization, Oorja is on track to become a leading provider of integrated clean energy solutions in rural India. As the business develops, Amit and Clementine will continue to explore the plausibility of franchising but will nonetheless continue to make a large, positive impact on the social, economic, and environmental sustainability of rural India.

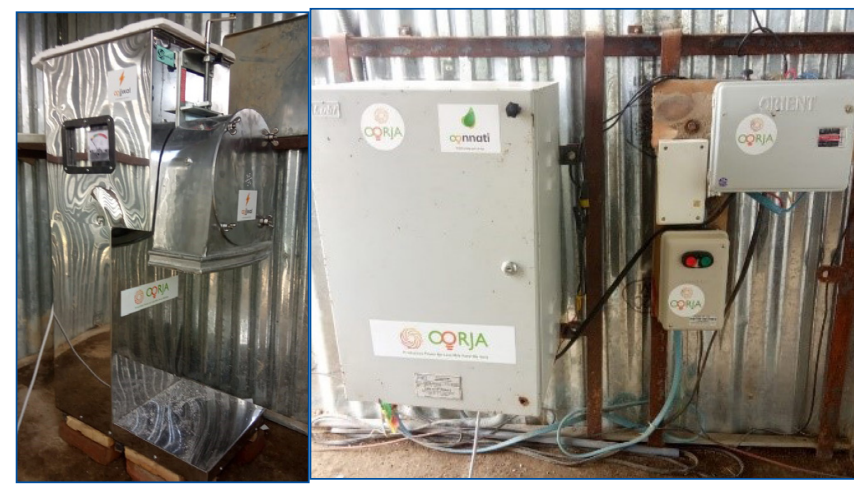

Oorja introduced a new agroprocessing service and operates two mills integrated with solar pumps. Photo shows the processing mill (left) and associated electronics (right) required to integrate the mill with the solar pump. Photo courtesy of Oorja.

\section{Methodology}

This case study was developed over a period of three months in the Summer of 2019 following the 20182019 Accelerator Program. It includes data from working sessions with company leaders, regular mentor/ mentee phone calls, and company research gathered throughout the nine-month accelerator. In-depth interviews with Oorja's leaders were supplemented with company-provided documents and secondary data. 


\section{References}

REC India, “Saubhagya Dashboard.” 2019. https://saubhagya.gov.in/ (accessed December 2020).

Sandwell, Philip, Chambon, Clementine, Saraogi, Amit, Chabenat, Apolline, Mazur, Marek, EkinsDaukes, Ned, Nelson, Jenny. "Analysis of Energy Access and Impact of Modern Energy Sources in Unelectrified Villages in Uttar Pradesh." October 27, 2016. https://www.sciencedirect.com/science/article/ pii/S0973082616303398 (accessed December 2020).

Smart Power India. "Rural Electrification in India. Customer Behaviour and Demand." February 2019. http://www.smartpowerindia.org/media/1230/report_ rural-electrification-in-india_customer-behaviourand-demand.pdf (accessed December 2020).

Sustainability Outlook. "Community Irrigation - The Next Frontier for Off-Grid Solar in India?" May 27, 2019. http://www.sustainabilityoutlook.in/content/ community-irrigation-\%E2\%80\%93-next-frontiergrid-solar-india-764606 (accessed December 2020).

University of Cambridge. "Solar Irrigation Solutions for Smallholder Farmers in India." June 5, 2019. https:// www.ceb.cam.ac.uk/news/news-list/social-enterprisesolar-irrigation-india (accessed December 2020).

\section{About the Authors}

Jill Howard is a 2019 graduate of the University of New Hampshire. Jill received a B.S. in Business Administration with a concentration in Social Innovation and Enterprise and a minor in Women's Studies. She worked for the Center for Social Innovation and Enterprise at UNH from January 2016 through 2019. She now works as a Sustainable Retail Reporting Analyst at Ahold Delhaize.
Fiona Wilson is the Director of the Sustainability Institute at the University of New Hampshire. Previously, from 2016-2020, she was the executive director of the Center for Social Innovation and Enterprise; she is also an affiliate clinical associate professor of Social Innovation, Social Entrepreneurship, and Sustainability, Department of Management at The Peter T. Paul College of Business and Economics at the University of New Hampshire (fiona.wilson@unh.edu).

E. Hachemi Aliouche is the director of the Rosenberg International Franchise Center and Associate Professor at The Peter T. Paul College of Business and Economics at the University of New Hampshire (hachemi.aliouche@unh.edu).

\section{A cknowledgements}

We are grateful to the funders that have made this work possible, including our lead funder the Peter T. Paul Innovation Fund at the Peter T. Paul College of Business \& Economics at the University of New Hampshire. We also acknowledge the support of the International Franchise Association's Social Sector Task Force, which provided volunteer mentor Greg Starbird of Starbird Consulting LLC who both served as an integral contributor to the Social Sector Franchise Accelerator and guided Oorja throughout the course of this case study. We also thank Oorja's Co-Founder and CEO Amit Saraogi for providing extensive access to the company information upon which this case study was based.

\section{TI University of New Hampshire \\ Carsey School of Public Policy}

The Carsey School of Public Policy at the University of New Hampshire is nationally recognized for its research, policy education, and civic engagement. The school takes on pressing public issues with unbiased, accessible, and rigorous research; builds the policy and political problem-solving skills of its students; and brings people together for thoughtful dialogue and practical problem-solving.

Huddleston Hall • 73 Main Street•Durham, NH 03824 • (603) 862-2821 • TTY UsERs: DIAL 7-1-1 OR 1-800-735-2964 (RELAY N.H.) 